\title{
MicroRNAs contribute to compensatory $\beta$ cell expansion during pregnancy and obesity
}

\author{
Cécile Jacovetti, ${ }^{1}$ Amar Abderrahmani, ${ }^{2}$ Géraldine Parnaud, ${ }^{3}$ Jean-Christophe Jonas, ${ }^{4}$ \\ Marie-Line Peyot, ${ }^{5,6}$ Marion Cornu, ${ }^{7}$ Ross Laybutt, ${ }^{8}$ Emmanuelle Meugnier, ${ }^{9}$ Sophie Rome, ${ }^{9}$ \\ Bernard Thorens, ${ }^{7}$ Marc Prentki, ${ }^{5,6}$ Domenico Bosco, ${ }^{3}$ and Romano Regazzi ${ }^{1}$
}

\begin{abstract}
${ }^{1}$ Department of Cell Biology and Morphology, University of Lausanne, Lausanne, Switzerland. ${ }^{2}$ University of Lille Nord de France, European Genomic Institute for Diabetes EGID FR 3508, UMR 8199, Lille, France. ${ }^{3}$ Cell Isolation and Transplantation Center, Department of Surgery, Geneva University Hospitals and University of Geneva, Geneva, Switzerland. ${ }^{4}$ Université catholique de Louvain, Institut de recherche expérimentale et clinique, Pôle d'endocrinologie, diabète et nutrition, Brussels, Belgium. ${ }^{5}$ Montreal Diabetes Research Center and CRCHUM, Montreal, Quebec, Canada.

${ }^{6}$ Departments of Nutrition and Biochemistry, University of Montreal, Montreal, Quebec, Canada. ${ }^{7}$ Center for Integrative Genomics, University of Lausanne, Genopode Building, Lausanne, Switzerland. ${ }^{8}$ Diabetes and Obesity Research Program, Garvan Institute of Medical Research, St. Vincent's Hospital, Sydney, New South Wales, Australia. 'Laboratory CarMen (INSERM 1060, INRA 1235, INSA), University of Lyon, Faculté de Médecine Lyon-Sud, Chemin du Grand Revoyet, Oullins, France.
\end{abstract}

\begin{abstract}
Pregnancy and obesity are frequently associated with diminished insulin sensitivity, which is normally compensated for by an expansion of the functional $\beta$ cell mass that prevents chronic hyperglycemia and development of diabetes mellitus. The molecular basis underlying compensatory $\beta$ cell mass expansion is largely unknown. We found in rodents that $\beta$ cell mass expansion during pregnancy and obesity is associated with changes in the expression of several islet microRNAs, including miR-338-3p. In isolated pancreatic islets, we recapitulated the decreased miR338-3p level observed in gestation and obesity by activating the G protein-coupled estrogen receptor GPR30 and the glucagon-like peptide 1 (GLP1) receptor. Blockade of miR-338-3p in $\beta$ cells using specific anti-miR molecules mimicked gene expression changes occurring during $\beta$ cell mass expansion and resulted in increased proliferation and improved survival both in vitro and in vivo. These findings point to a major role for miR-338-3p in compensatory $\beta$ cell mass expansion occurring under different insulin resistance states.
\end{abstract}

\section{Introduction}

Diabetes mellitus is a metabolic disorder characterized by chronic hyperglycemia resulting from defective function and/or loss of insulin-secreting $\beta$ cells $(1,2)$. These cells, located within the islets of Langerhans, display a slow turnover rate $(3,4)$. Conditions such as pregnancy and obesity are associated with a diminished sensitivity of insulin target tissues and a consequent rise in the insulin demand that is compensated for by an increase in the number and secretory activity of $\beta$ cells $(2,5-7)$. Genetically predisposed individuals exposed to physiological or environmental conditions that trigger insulin resistance fail to compensate for the increased insulin demand and are prone to developing gestational and type 2 diabetes (8). Detailed knowledge of the mechanisms controlling compensatory $\beta$ cell mass expansion would allow a better understanding of the events underlying the development of gestational and type 2 diabetes and provide the basis for the design of new strategies to prevent and treat these diseases.

Pregnancy is the strongest physiological stimulus inducing $\beta$ cell mass plasticity (9-11). In rodents, $\beta$ cell mass expansion peaks at day 14 of gestation $(9,12)$ and occurs through a combination of mechanisms, including an increase in $\beta$ cell replication and $\beta$ cell hypertrophy and a minimal rate of $\beta$ cell apoptosis (12). The mass of $\beta$ cells and their secretory activity returns to prepregnancy levels within the first 10 days after parturition $(12,13)$. Different mechanisms have been proposed to control adaptive $\beta$ cell mass plasticity. Among these, the most thoroughly investigated are those elicited by prolactin and placental lactogen. In fact, pregnant mice lacking the prolactin receptor, which mediates the

Conflict of interest: The authors have declared that no conflict of interest exists. Citation for this article: JClin Invest. 2012;122(10):3541-3551. doi:10.1172/JCI64151. action of both lactogenic hormones, develop gestational diabetes (14). Lactogenic hormones trigger $\beta$ cell mass expansion through different mechanisms, including reduction of Menin, a protein exerting an inhibitory action on insulin secretion and $\beta$ cell proliferation (15); induction of the transcription factor FoxM1 (16); and activation of a paracrine/autocrine loop leading to increased serotonin production by $\beta$ cells $(17,18)$. At least some of these signaling cascades may not be restricted to pregnancy and may also operate during compensatory $\beta$ cell proliferation associated with obesity $(15,19)$. Beside lactogenic hormones, additional factors have been proposed to contribute to adaptive changes in $\beta$ cell mass, including steroid hormones and lipids $(20,21)$. So far, the mechanisms underlying the effect of these factors on $\beta$ cell expansion are poorly understood.

microRNAs (miRNAs) are small noncoding RNAs acting as translational repressors that play a major role in the control of cell proliferation and survival. These regulatory molecules bind to the $3^{\prime}$ untranslated region of target mRNAs, leading to translational inhibition and/or messenger degradation $(22,23)$. In pancreatic $\beta$ cells, miRNAs govern the expression of key genes essential for insulin secretion and for cell survival (24-29). Several studies reported changes in the expression of islet miRNAs in animal models of diabetes with detrimental effects on the secretory activity and survival of $\beta$ cells $(30,31)$. Moreover, leptin-deficient obese mice lacking miR-375 failed to compensate for insulin resistance and developed a severe diabetic phenotype (32). These observations prompted us to investigate whether changes in miRNA expression contribute to compensatory $\beta$ cell mass expansion during pregnancy. Our study led us to identify miRNAs regulated by estradiol and incretins that are differentially expressed in maternal islets during pregnancy. Reduction of the level of one of these 


\section{A}
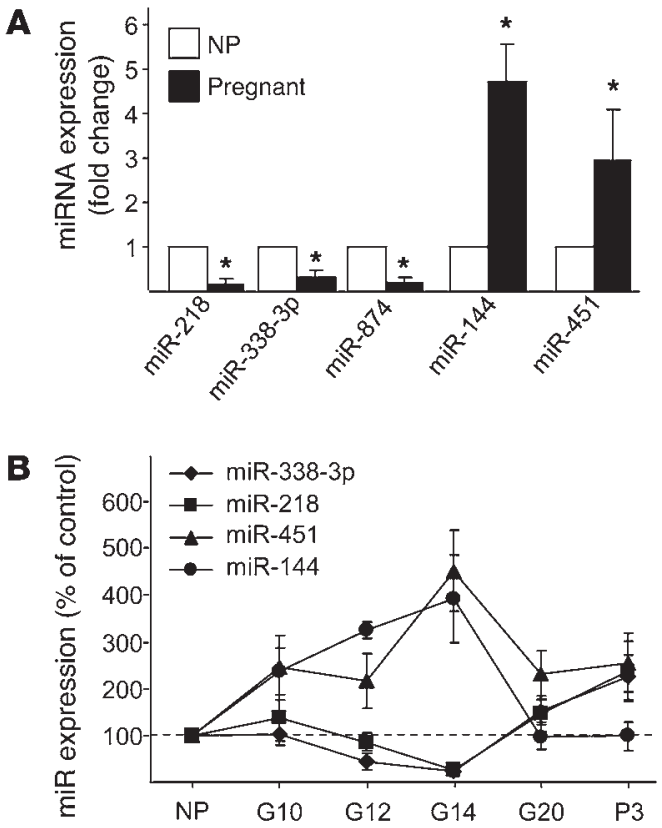

miRNAs - miR-338-3p, which mimics the conditions observed during gestation - promoted $\beta$ cell proliferation and protected the cells against apoptosis. Interestingly, the level of this miRNA was also reduced in the islets of other animal models characterized by $\beta$ cell mass expansion, suggesting a general role for miR-338-3p in this important compensatory mechanism.

\section{Results}

Changes in miRNA expression in pancreatic islets during pregnancy. To identify miRNAs potentially involved in $\beta$ cell mass expansion during pregnancy, we analyzed by microarray the level of 350 miRNAs in islets of rats at day 14 of gestation (corresponding to the peak of $\beta$ cell mass expansion; ref. 9) and age-matched nonpregnant female rats. Of the 203 miRNAs expressed at detectable levels in the islet preparations, 7 displayed changes at day 14 of gestation (Supplemental Table 1; supplemental material available online with this article; doi:10.1172/JCI64151DS1). Significant differences in the level of 5 of these miRNAs were confirmed by quantitative realtime PCR (qRT-PCR; Figure 1A). miR-874, which was expressed at very low levels in the islets, as well as miR-325-5p and miR-188, whose changes were not confirmed by qRT-PCR (data not shown), were not investigated further. Of the 4 retained miRNAs, miR-218 and miR-338-3p were downregulated, whereas miR-144 and miR451 were upregulated, at day 14 . Analysis of the expression of these miRNAs at different stages of gestation revealed that the variations in expression correlated with the modifications in $\beta$ cell mass, peaking at day 14 and returning close to pregestational levels at the end of the pregnancy and at day 3 postpartum (Figure 1B).

Functional roles of the identified miRNAs in pancreatic islet cells. To determine the potential involvement of the selected miRNAs in the control of $\beta$ cell functions, we mimicked the changes in expression observed during pregnancy by transfecting dissociated rat and human islet cells or the insulin-secreting cell lines INS832/13 and MIN6B1 with oligonucleotides that either specifically block (anti$\mathrm{miR}$ ) or increase (oligonucleotide mimic) the level of the miRNAs. The efficacy of these treatments was verified by qRT-PCR (Supple-

\section{Figure 1}

Identification of miRNAs differentially expressed in the islets of pregnant rats. (A) Expression of the indicated miRNAs was measured by qRT-PCR in the islets of female rats at day 14 of gestation. Results are expressed as fold changes and correspond to the mean \pm SD of 4 nonpregnant (NP) control and 4 pregnant rats. (B) Expression of the indicated miRNAs was determined by qRT-PCR in islets from nonpregnant rats and from pregnant rats at days 10,12, 14, and 20 of gestation ( $\mathrm{G} 10, \mathrm{G} 12, \mathrm{G} 14$, and $\mathrm{G} 20$, respectively) and 3 days postpartum (P3). Results (mean \pm SD of 4 animals per group) are expressed as percent of the level of each miRNA in nonpregnant rats. ${ }^{*} P<0.05$ vs. nonpregnant, ANOVA. mental Figure 1). We first assessed whether changes in expression mimicking those observed during pregnancy affect glucose-stimulated insulin secretion. Inhibition of miR-218 and miR-338-3p or overexpression of miR-144 and miR-451 in dissociated rat islet cells and MIN6 cells did not significantly alter insulin content (Supplemental Figure 2). Moreover, insulin release under basal conditions and upon glucose stimulation was unaffected (Supplemental Figure 2). Next we investigated whether the miRNAs contribute to the regulation of $\beta$ cell proliferation. Changes in the level of miR-218, miR-144, and miR-451 did not significantly modify the number of $\mathrm{Ki} 7^{+}$or $\mathrm{BrdU}^{+}$INS832/13 cells (Figure 2, A and $\mathrm{B}$ ). In contrast, reduction of miR-338-3p expression led to an increase in the number of proliferating INS832/13 cells (Figure 2, $\mathrm{A}$ and $\mathrm{B}$ ). Analogous effects were observed in dissociated rat islet cells (Figure 2C). In contrast, modulation of the 4 miRNAs did not significantly change pancreatic $\alpha$ cell proliferation (Supplemental Figure 3). To verify that the reduction of miR-338-3p also retains proproliferative properties in vivo, dissociated rat islet cells transfected with anti-miR-338-3p were cultured for 2 days to induce pseudoislet aggregate formation, then transplanted under the rat kidney capsule. We found that blockade of miR-338-3p resulted in an approximately $80 \%$ increase in proliferating insulin ${ }^{+}$cells (Figure 2D). Proliferation of glucagon ${ }^{+}$cells was again unaffected (Figure 2D). The effect of miR-338-3p downregulation on proliferation was also tested in human $\beta$ cells. However, in line with the data available in the literature $(33,34)$, neither different hormones capable of triggering proliferation of rodent $\beta$ cells nor miR-338$3 p$ downregulation were capable of eliciting replication of human $\beta$ cells (Supplemental Table 2 ).

$\beta$ cell mass expansion during pregnancy is thought to result from an increase in proliferation combined with a low apoptotic rate. To explore a possible involvement of the miRNAs in apoptosis, dissociated rat and human islet cells were transfected with anti-miR-218 and anti-miR-338-3p or with oligonucleotides that cause miR-144 and miR-451 overexpression. The cells were then incubated in the presence of proinflammatory cytokines, includ- 
A
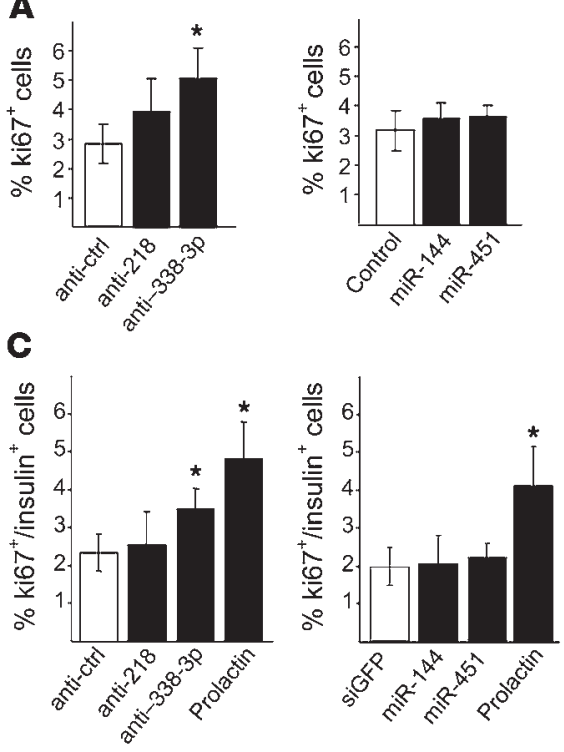

B

D
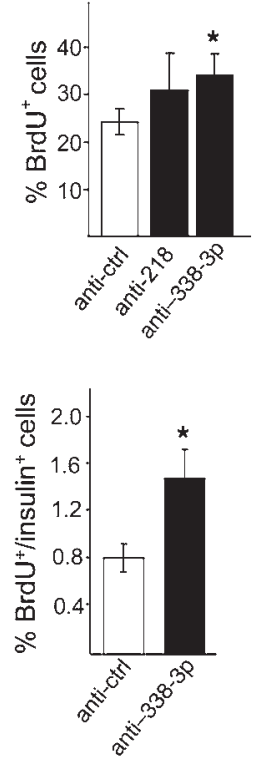

\section{Figure 2}

Effect of miRNA level modification on $\beta$ cell proliferation. (A and B) INS832/13 cells were transfected with a scrambled anti-miR (anti-ctrl) or with anti-miR specifically blocking miR-218 or miR-338-3p (left), or with oligonucleotides leading to miR-144 or miR-451 overexpression or an siRNA directed against siGFP as control (right). (C) Dissociated rat islet cells were transfected with anti-miRs (left) or oligonucleotide mimics (right) to modulate the expression of the indicated miRNAs. Cells treated with prolactin $(500 \mathrm{ng} / \mathrm{ml}$ for 48 hours) were used as positive control for proliferation. The fraction of proliferating insulin ${ }^{+}$cells was assessed by scoring Ki67+ (A and $\mathbf{C}$ ) or $\mathrm{BrdU}^{+}(\mathbf{B})$ cells. Data are mean \pm SD of 6 independent experiments. ${ }^{*} P<0.05$ vs. control, ANOVA. (D) Dissociated rat islet cells were transfected with a scrambled anti-miR or with anti-miR-338-3p. They were then cultured for 2 days to induce formation of pseudoislet aggregates and transplanted under the renal capsule of congenic rats. 3 days later, the fraction of proliferating $\beta$ (left) and $\alpha$ (right) cells in the transplanted islets was assessed by scoring the insulin+ or glucagon ${ }^{+}$cells incorporating BrdU, respectively. Results are mean \pm SD of 3 independent experiments. ${ }^{*} P<0.05$ vs. control, ANOVA.

ing IL- $1 \beta$, TNF- $\alpha$, and IFN- $\gamma$. As expected $(35,36)$, prolonged exposure to cytokines triggered $\beta$ cell apoptosis while the number of necrotic cells remained stable (Figure 3). Anti-miR-338-3p treatment and miR-451 overexpression in rat islet cells resulted in a striking reduction in cytokine-induced apoptosis, as assessed by annexin $\mathrm{V}$ staining and by counting the cells displaying picnotic nuclei (Figure 3, A and B). The protective effect of miR-338-3p downregulation and miR-451 overexpression was not selective for cytokines and was also observed when apoptosis was triggered by incubating rat islet cells with palmitate (Figure 3C). Similar data were obtained with dissociated human islet cells exposed to cytokines (Figure 3D). Overexpression of miR-338-3p in dispersed rat islet cells led to an increase in apoptosis (Figure 3E), which confirmed the involvement of this miRNA in cell survival. Taken together, these findings support the idea that changes in the level of miR-338-3p and miR-451 can contribute to adaptive $\beta$ cell mass plasticity that occurs during pregnancy.

17- $\beta$ estradiol downregulates miR-338-3p expression by activating GPR30 signaling. Pregnancy is characterized by a plasmatic increase in maternal hormones, including prolactin (PRL), progesterone, and $17-\beta$ estradiol (37). To gain insight into the mechanisms regulating the expression of the selected miRNAs, islets and insulin-secreting cell lines were exposed for 48 hours to these maternal hormones. We found that prolactin (which is known to trigger $\beta$ cell prolif-
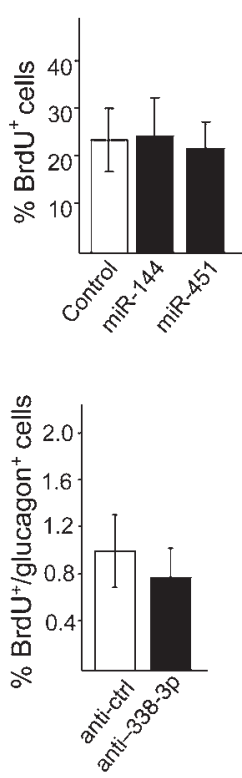

eration; refs. 20, 38), and progesterone did not affect miR-338-3p levels in INS832/13 cells (data not shown). PRL was also without effect on miR-218, miR-144, and miR451 (data not shown). Estrogens have antiapoptotic and proproliferative effects on $\beta$ cells $(20,39-41)$. Exposure to $100 \mathrm{nM} 17-\beta$ estradiol reduced by about half the level of miR-338-3p in INS832/13 cells (data not shown) and in rat and human islet cells (Figure 4, A and B). A similar decrease was observed upon incubation at lower estradiol concentrations, namely, 1 or $10 \mathrm{nM}$ (data not shown). Treatment of rat islets with 17- $\beta$ estradiol did not affect miR-218 and miR-451, but significantly upregulated miR-144 (Supplemental Figure 4). Similar results were obtained with human islets (data not shown). Overexpression of miR338-3p prevented the increase in proliferating INS832/13 cells and primary rat $\beta$ cells elicited by $17-\beta$ estradiol (Figure $4, C$ and $D$ ), which indicates that a reduction in the level of this miRNA is required for the proliferative effect of the hormone.

Estrogens exert their action either by binding to conventional $E R \alpha / \beta$ receptors or by activating the $G$ protein-coupled receptor GPR30 (40, 42-45). This transmembrane receptor is coupled to Gs and triggers a rise in cAMP and activation of the PKA signaling cascade (46). We found that miR-338$3 \mathrm{p}$ expression was downregulated upon exposure of rat islet cells to dibutyryl cAMP (Figure 5A). Moreover, treatment of dispersed rat or human islet cells with the PKA inhibitor $\mathrm{H} 89$ prevented the effect of $17-\beta$ estradiol on miR-338-3p expression (Figure 5, B and C), suggestive of a possible involvement of GPR30. We found that the expression of GPR30 increased during pregnancy, peaking at day 14 of gestation and returning close to basal level at the end of gestation (Figure 5D). To directly assess whether estrogens control the level of miR-338-3p via activation of GPR30, rat islets were incubated with the GPR30 agonist G1 (47). Indeed, G1 treatment reduced miR-338-3p levels by about 35\% (Figure 5E). Moreover, siRNAs directed against GPR30 were able to prevent the decrease of miR-338-3p elicited by 17- $\beta$ estradiol (Figure 5, $F$ and G). Similar results were obtained when GPR30 activation in rat islet cells was blocked using the specific antagonist G15 (data not shown). In contrast, Fulvestrant (ICI 182-780), an antagonist of conventional $E R \alpha / \beta$ receptors, did not affect estradiol-induced miR-338-3p downregulation (Figure $5 \mathrm{H}$ ).

Downstream signaling elicited by miR-338-3p downregulation. Since miR-338-3p appears to play an important role in the control of $\beta$ cell mass expansion, we searched for its molecular target(s). During pregnancy, several key genes known to regulate $\beta$ cell proliferation and/or survival displayed expression profiles that were inversely correlated to the level of miR-338-3p (Figure 6A). Blockade of miR-338-3p in dissociated rat or human islet cells was sufficient to mimic several of the changes occurring during pregnancy, including an increase of Birc5, Igf1r, Irs2, Bcl2, and Bcl-xl and a decrease of 
A
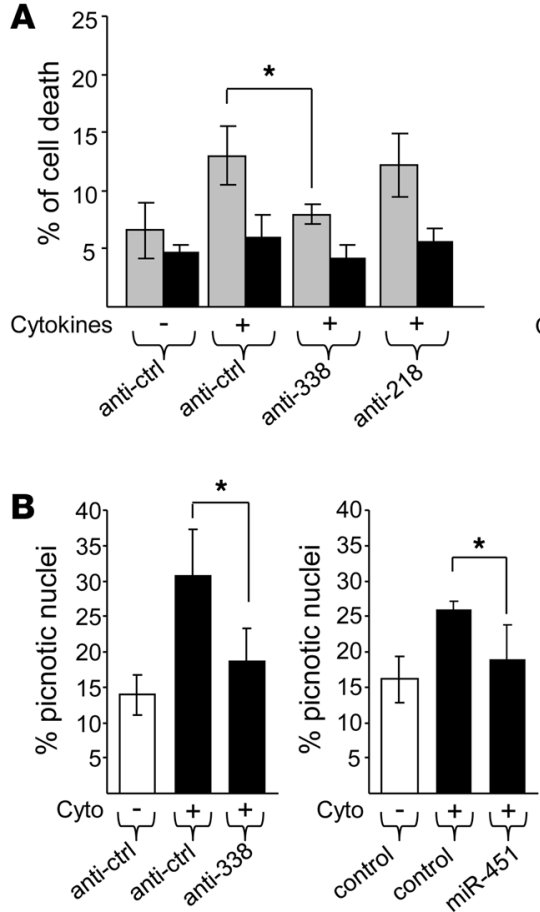

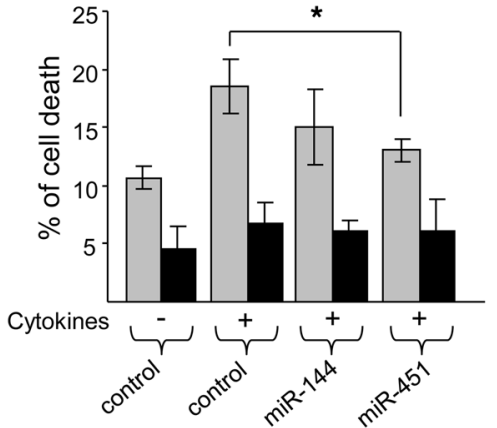

C

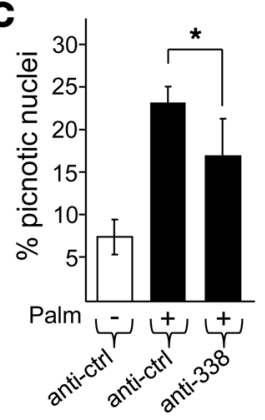

Figure 3

Inhibition of miR-338-3p protects $\beta$ cells against apoptosis. Dissociated rat $(\mathbf{A}-\mathbf{C}$ and $\mathbf{E})$ and human (D) islet cells were transfected with anti-miRs (left) or oligonucleotide mimics (right) to modulate the expression of the indicated miRNAs. Cells were incubated for 24 hours with or without a mix of proinflammatory cytokines (10 ng/ml TNF- $\alpha, 0.1 \mathrm{ng} / \mathrm{ml} \mathrm{IL-1 \beta ,30} \mathrm{ng/ml} \mathrm{IFN-} \gamma$; A, B, D, and E) or for 48 hours either with $0.5 \%$ BSA or with $0.5 \%$ BSA coupled to $0.5 \mathrm{mmol} / \mathrm{l}$ palmitate (C). Apoptosis was assessed either by labeling the cells with annexin $\mathrm{V}(\mathbf{A})$ or by staining picnotic nuclei (B-E). Annexin $V$ and propidium iodide staining allowed for assessment of apoptosis (gray bars) and necrosis (black bars), respectively. Data are mean \pm SD of 4 independent experiments. ${ }^{*} P<0.05$, ANOVA.
D

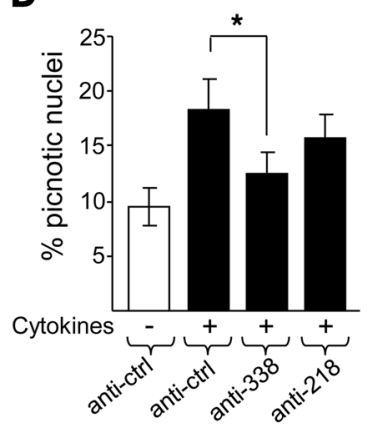

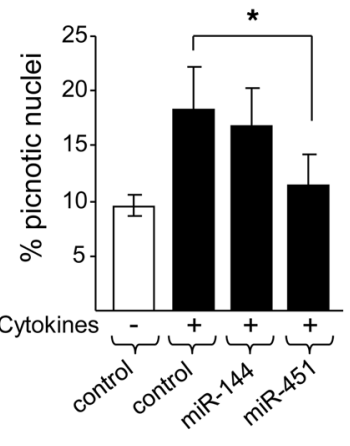

E

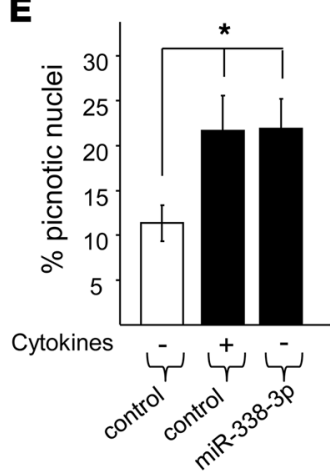

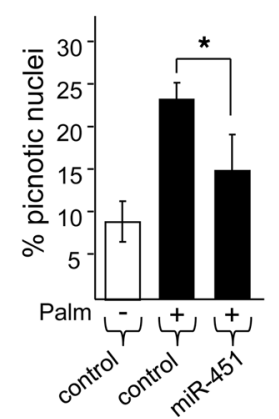

Bad (Figure 6, B and C). For Birc5, Igf1r, and Bcl2, which displayed the most striking variations in response to miR-338-3p blockade, the changes observed at the mRNA level were confirmed at the protein level (Supplemental Figure 5). Any of these genes are predicted targets of miR-338-3p (http://www.targetscan.org/), and they are probably not directly controlled by the miRNA. The phenotypic changes observed most likely result from the effect of miR-3383 p on multiple genes and not from the effect of the miRNA on a single target. Thus, instead of searching for individual targets, we attempted to obtain a global picture of the genes affected by miR338-3p by performing transcriptomic analysis of INS832/13 cells in which miR-338-3p was downregulated. Bioinformatic analysis of the 699 genes differentially expressed in cells with reduced miR338-3p level revealed an enrichment of genes involved in cell cycle and cell growth (Supplemental Table 3).

miR-338-3p downregulation occurs in the islets of other animal models displaying $\beta$ cell mass expansion. To assess whether reduction of $\mathrm{miR}$ $338-3 \mathrm{p}$ is a general phenomenon associated with increases in $\beta$ cell mass, we measured the level of this miRNA in the islets of 2 animal models characterized by insulin resistance and compensatory $\beta$ cell mass expansion. We first measured miR-218, miR-338-3p, miR-144, and miR-451 expression in islets of mice fed a high-fat diet (HFD) for 8 weeks. These mice are obese, hyperinsulinemic, and glucose intolerant and display increased $\beta$ cell mass (48). In HFD-fed mice, the level of miR-218 and miR-144 were unchanged, whereas expression of $\mathrm{miR}-451$ was increased by $60 \% \pm 36 \%$ $(P<0.05 ; n=4)$. In the islets of these mice, expression of miR-338$3 \mathrm{p}$ decreased 2- to 3-fold compared with mice fed a normal diet (Figure 7A). In the islets of 6-week-old $d b / d b$ mice, which lack the leptin receptor (49), expression of miR-338-3p was also reduced by about $80 \%$ (Figure 7B). In contrast, the level of the other 3 miRNAs was unaffected (data not shown). At this age, $d b / d b$ mice are obese, but still normoglycemic. These findings indicate that changes in miR-338-3p expression are not restricted to pregnancy, but also occur in other physiopathological conditions characterized by insulin resistance and compensatory $\beta$ cell mass expansion.

miR-338-3p levels are controlled by incretins. GPR30 expression is unchanged in the islets of diet-induced obese mice and $d b / d b$ mice (Supplemental Figure 6). In view of these findings, estrogens are unlikely to mediate the decrease in miR-338-3p observed in obese 
A

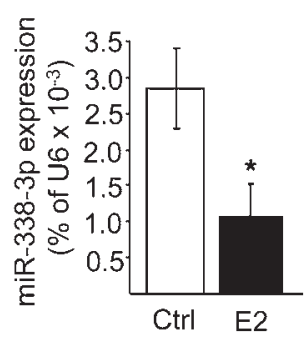

B

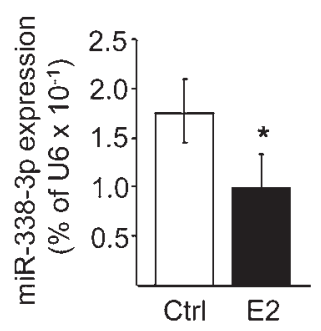

C

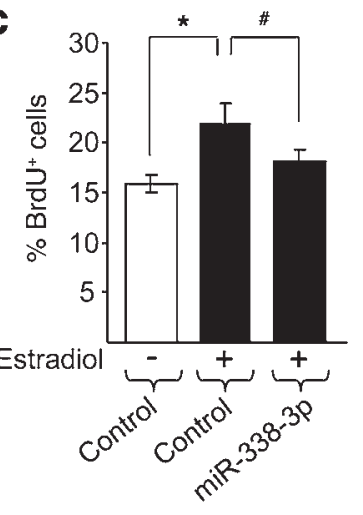

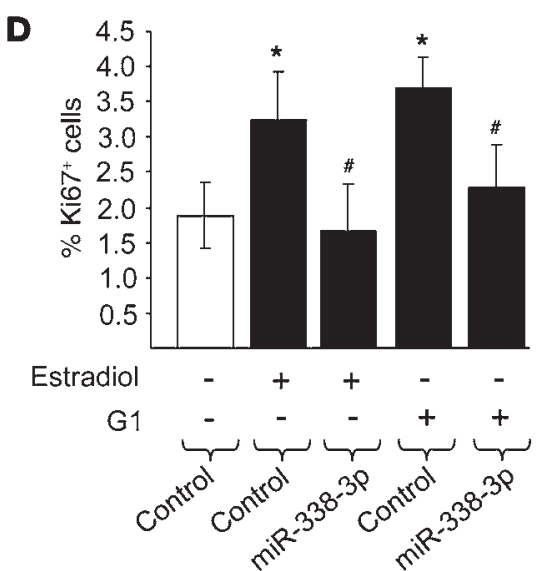

Figure 4

miR-338-3p is downregulated by $17-\beta$ estradiol, and its overexpression impairs the proliferative effect of the hormone. miR-338-3p expression was measured in rat (A) and human (B) islets incubated with vehicle control or with $100 \mathrm{nM}$ estradiol (E2) for $48 \mathrm{hours}$. INS832/13 cells (C) and dispersed rat islet cells (D) were transfected with a control oligonucleotide or with an oligonucleotide leading to miR-338-3p overexpression. Cells were then incubated for 48 hours in the presence or absence of $100 \mathrm{nM}$ estradiol or $100 \mathrm{nM}$ G1. Proliferation was assessed by scoring the fraction of $\mathrm{BrdU}^{+}(\mathbf{C})$ or $\mathrm{Ki} 67^{+}$(D) cells. Data are mean $\pm \mathrm{SD}$ of 5 (C) or 6 (D) independent experiments. ${ }^{*} P<0.05$ vs. control, \# $P<0.05$ vs. estradiol or G1 alone, ANOVA.

mice. Therefore, we searched for other signaling pathways potentially regulating the expression of the miRNA. The incretin glucagon-like peptide 1 (GLP1) is known to promote $\beta$ cell proliferation and to protect the cells against apoptosis through a cAMP-dependent mechanism $(50,51)$. We found that exposure of rat or human islets to the GLP1 analog exendin-4 decreased the level of miR-3383 p by about 2.5-fold (Figure $8, \mathrm{~A}$ and B). miR-144 and miR-451 expression were increased by exendin- 4 treatment, whereas miR218 was unaffected by the GLP1 analog (Supplemental Figure 7). In the islets of Glp1r/-Gip1r/- mice, which display elevated rates of $\beta$ cell death and impaired insulin secretion (52), this miRNA was upregulated about 2.3-fold (Figure 8C), in agreement with an involvement of incretins in the control of miR-338-3p expression.

The beneficial effects of GLP1 on $\beta$ cell function relies on an autocrine loop involving the upregulation of Igf1r and Irs2. As mentioned above, blockade of miR-338-3p mimicked this effect of GLP1 and led to an increase of Igf1r and Irs2 expression (Figure 6, $\mathrm{B}$ and $\mathrm{C}$ ). In addition, we found that overexpression of miR-338-3p prevented the induction of IgfIr and Irs2 (Figure 8D) and the rise in proliferation observed in response to exendin-4 (Figure 8, E and F). Taken together, these results strongly support the hypothesis of miR-338-3p involvement in the effects of incretins on $\beta$ cells.

\section{Discussion}

miRNAs are small noncoding RNAs that play important roles in the regulation of $\beta$ cell function, including proliferation and survival $(27,32)$. To our knowledge, their potential involvement in compensatory $\beta$ cell expansion had not previously been investigated. The present study revealed changes in the expression of a subset of islet miRNAs that correlate with the adaptation of $\beta$ cell mass during different stages of rat pregnancy. In fact, the peak of $\beta$ cell mass expansion at day 14 of gestation corresponded to maximal upregulation of miR-144 and miR-451 and maximal downregulation of miR-218 and miR-338-3p. These expression changes were reversed at the end of pregnancy, when $\beta$ cell mass returned to pregestation levels. At least part of these modifications in miRNA expression caused adaptations in cellular functions, with a potential effect on islet $\beta$ cell number. Indeed, miR-338-3p downregulation promoted proliferation and protected rat $\beta$ cells against apoptosis, and a rise of miR-451 was associated with improved resistance of rat $\beta$ cells to proapoptotic stimuli. Conversely, upregulation of miR-338-3p triggered apoptosis, mimicking the reduction of $\beta$ cells observed at the end of pregnancy (13). The effect on apoptosis was also confirmed in human $\beta$ cells, but anti-miR-338-3p treatment was not sufficient to trigger replication of these cells. This result was somehow expected, because proliferation of human $\beta$ cells is an extremely rare event $(33,34)$; even exendin, estradiol, and the GRP30 ligand G1, which are capable of decreasing miR-338-3p expression under the same experimental conditions, failed to elicit proliferation. Thus, the potential role of miR-338-3p on human $\beta$ cell proliferation will need to be reevaluated once better approaches to assess replication of these cells are developed.

Interestingly, knockdown of miR-338-3p triggered proliferation of rat $\beta$ cells, but not of $\alpha$ cells. The precise causes of this cell-selective effect will need to be addressed in future studies. The global miRNA expression profile of primary $\alpha$ and $\beta$ cells is not yet available, and it is possible that miR-338-3p is expressed at different levels in glucagon-secreting cells than in insulin-secreting cells or that the function of this miRNA is counterbalanced by other miRNAs. Another attractive possibility is that the signaling pathways elicited upon miR-338-3p downregulation are not operating in $\alpha$ cells. Indeed, we showed that at least part of the effect of antimiR-338-3p on $\beta$ cells was mediated through induction of Igf1r, a receptor that seems to not be involved in $\alpha$ cell proliferation (53).

Despite these proliferative and antiapoptotic effects, miR-338-3p downregulation and miR-451 overexpression did not significantly affect insulin content and glucose-induced insulin secretion, which indicates that upon changes in the level of these miRNAs, the $\beta$ cells retained a fully differentiated phenotype. Taken together, these results are consistent with these miRNAs contributing to maternal adaptations in $\beta$ cell mass that occur during gestation. Modulation of the level of miR-218 or miR-144 in vitro did not 

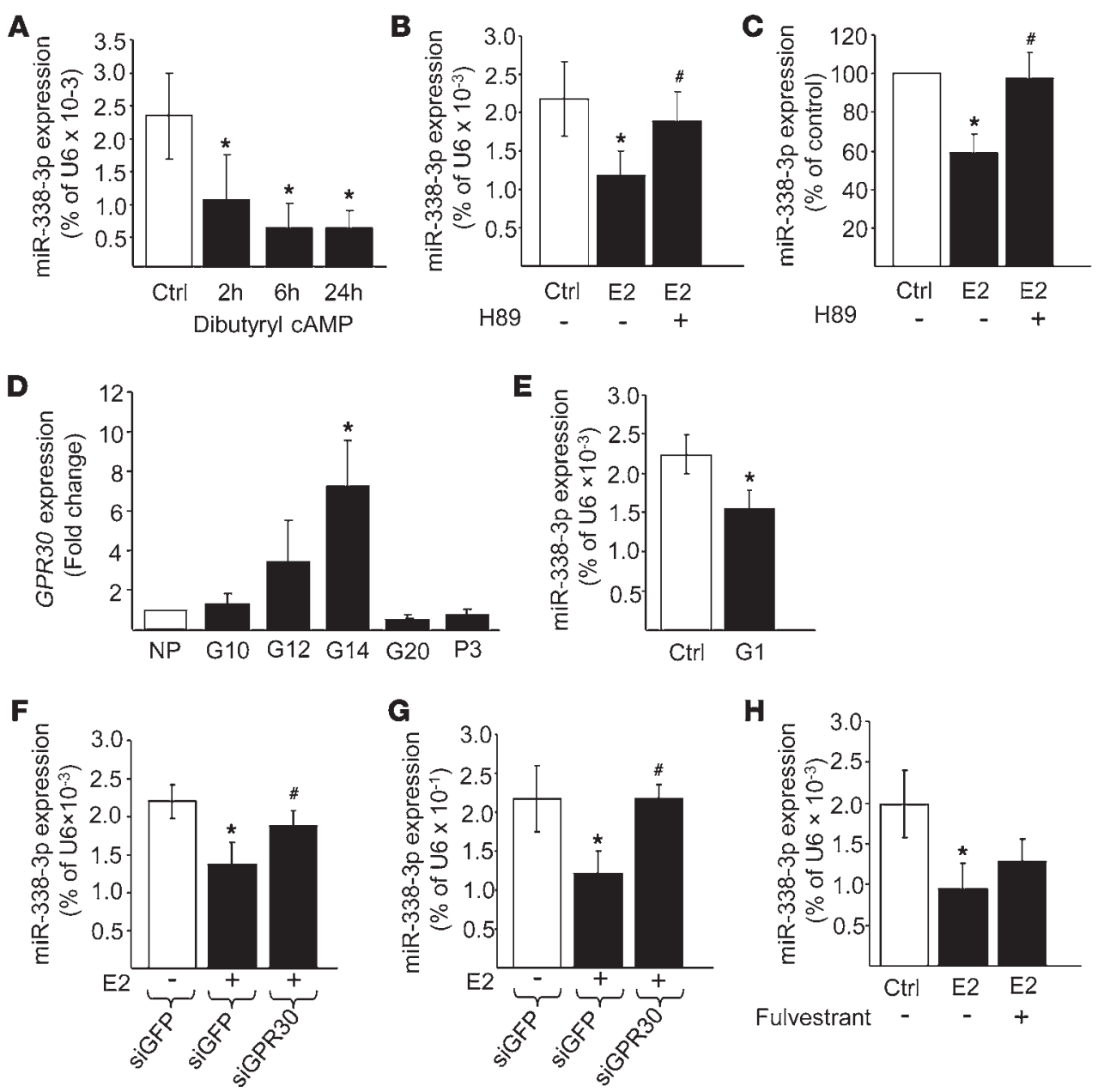

\section{Figure 5}

$17-\beta$ estradiol controls miR-338-3p expression through activation of GPR30. (A-C and $\mathbf{E}-\mathbf{H})$ miR-338-3p levels were assessed by qRT-PCR and expressed as a percentage of U6. Rat islets were (A) cultured in the presence of $1 \mathrm{mM}$ dibutyryl cAMP for 0 (Ctrl), 2, 6, and 24 hours; (B)

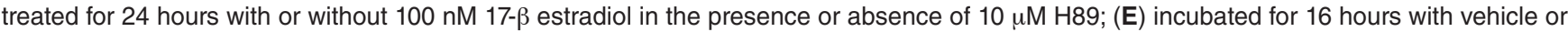
$100 \mathrm{nM} \mathrm{G1} ;(\mathbf{F})$ transfected with siRNAs directed against GFP or GPR30, and the following day incubated with or without estradiol for 48 hours; or $(\mathbf{H})$ cultured for 24 hours with $100 \mathrm{nM} 17-\beta$ estradiol in the presence or absence of $100 \mathrm{nM}$ Fulvestrant. (C) Human islets treated as in B. (G) INS832/13 cells transfected as in F. (D) Expression of GPR30 in islets from nonpregnant rats and of rats at 10, 12, 14, and 20 days of pregnancy and 3 days postpartum. Results are expressed as fold change compared with the level in nonpregnant rats. Data are mean \pm SD $(n=3[\mathbf{A}$ and C]; 4 [B, D, E, G, and H]; 5 [F]). ${ }^{*} P<0.05$ vs. control, ${ }^{\#} P<0.05$ vs. estradiol, ANOVA.

result in detectable modifications in the activities of rat islet cells or INS832/13 cells. However, a contribution of these miRNAs to $\beta$ cell adaptation in vivo cannot be excluded at this stage.

In view of its multiple effects on $\beta$ cell activities, we attempted to elucidate the mode of action of miR-338-3p. Blockade of this miRNA had a strong effect on a set of genes playing key roles in $\beta$ cell proliferation and survival. Birc5 (also known as Survivin) and Foxm1 were among the most interesting genes upregulated in $\beta$ cells upon blockade of miR-338-3p: the former has antiapoptotic and proproliferative properties, and the latter promotes $\beta$ cell proliferation (19, 54). Both have been shown to increase in islets from animal models characterized by $\beta$ cell expansion and regeneration, such as pregnant mice at day 14 of gestation and $o b / o b$ mice $(16,19,55)$. Other adaptations in gene expression consistent with the increased proliferative capacity and improved survival of $\beta$ cells included elevated levels of Igf $1 r$ and Irs 2 and a rise in the antiapoptotic protein Bcl2.
Compensatory $\beta$ cell mass expansion during pregnancy is thought to be triggered by an increase in maternal hormones. Lactogens are generally recognized as key inducers of this process $(15$, $17,56)$. Indeed, pregnant mice lacking the prolactin receptor, which mediates the action of lactogenic hormones, develop gestational diabetes (14). Despite increasing plasmatic levels of estradiol during pregnancy and the capacity of this hormone to increase replication and improve survival and function of insulin-secreting cells in vitro and in vivo $(20,37,40,57)$, the contribution of estrogens to adaptive $\beta$ cell mass expansion had thus far remained elusive. Our study unveiled a possible role for estradiol in pregnancy-associated $\beta$ cell mass expansion through repression of miR-338-3p. Reduction of miR-338-3p level in rat islet cells mimicked the phenotypic changes observed upon estradiol treatment and, conversely, overexpression of miR-338-3p prevented estradiol-induced proliferation. Our data indicate that the effect of estradiol is not mediated 
A

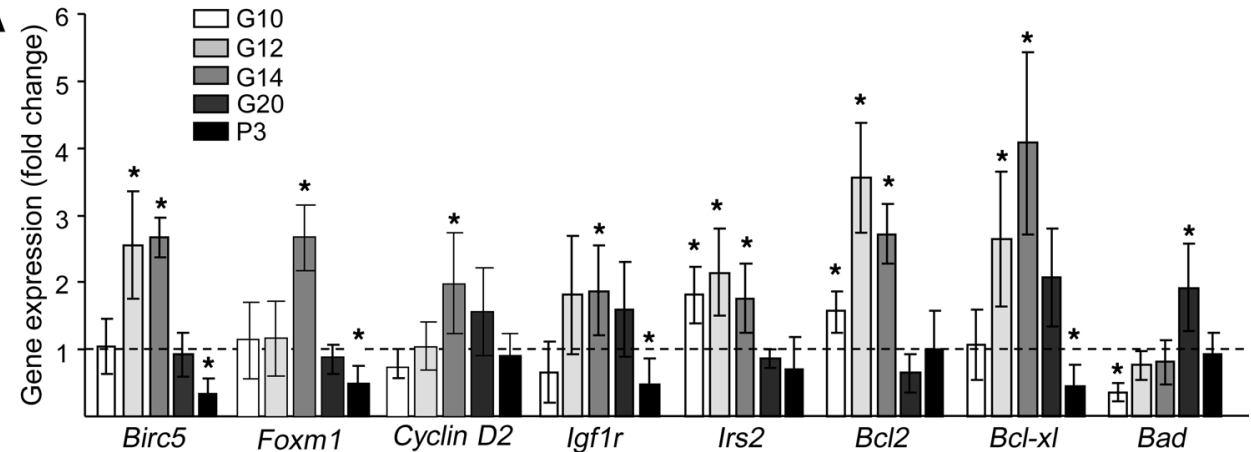

B

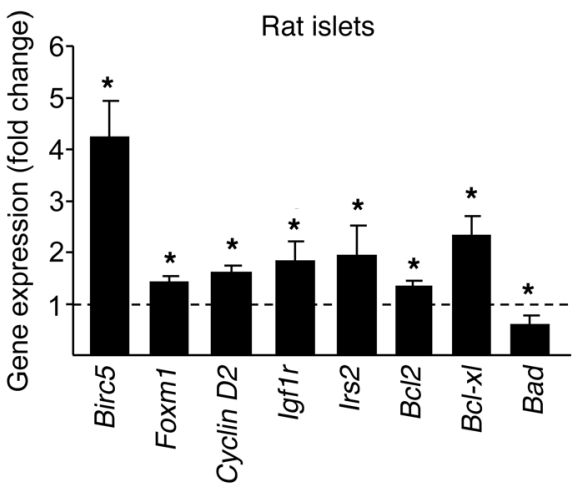

C

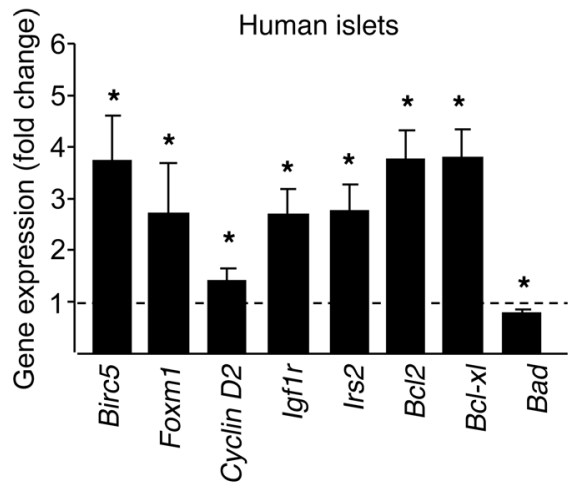

Figure 6

miR-338-3p inhibition elicits gene expression changes analogous to those observed in islets of pregnant rats. (A) Birc5, Foxm1, Cyclin D2, Igf1r, Irs2, Bcl2, Bcl-xl, and Bad expression in islets of pregnant rats at different stages of gestation were measured by qRT-PCR. Results are presented as fold changes compared with nonpregnant rats and represent mean \pm SD of 4 rats per group. Rat (B) and human (C) islet cells were transfected with antimiR-338-3p. Birc5, Igf1r, Irs2, Bcl2, $\mathrm{BCl}-\mathrm{xl}$, and $\mathrm{Bad}$ expression were measured by qRT-PCR and compared with the level in cells transfected with a scrambled anti-miR. Data are expressed as fold changes and represent mean \pm SD of 4 (B) or $3(\mathbf{C})$ independent experiments. ${ }^{\star} P<0.05$ vs. control, ANOVA. through conventional $E R \alpha / \beta$ receptors, but rather occurs through activation of GPR30 $(46,58,59)$. In fact, the effect of estradiol was cAMP-dependent and was blocked by PKA inhibitors. Moreover, the reduction of miR-338-3p expression observed upon estradiol treatment was mimicked by a GPR30 agonist, and silencing of the receptor by RNA interference eliminated the effect of the hormone. Moreover, GPR30 expression was strongly upregulated during pregnancy and correlated with $\beta$ cell mass expansion. Thus, the effect of estradiol is likely to be restricted to pregnancy, and miR338-3p levels are probably not influenced by the fluctuations of this hormone during oestrus. GPR30 knockout mice display alterations in blood glucose homeostasis $(42,60)$, but the potential role of this receptor in the control of $\beta$ cell mass in vivo has not been investigated. Because of the broad tissue expression of GPR30, a definitive assessment of the contribution of this receptor in compensatory $\beta$ cell mass expansion during pregnancy will necessitate the generation of $\beta$ cell-specific knockouts.

A mechanism analogous to the one we uncovered for compensatory $\beta$ cell mass expansion during pregnancy is likely to operate in other conditions characterized by insulin resistance, such as obesity. Indeed, miR-338-3p was downregulated in young prediabetic $d b / d b$ mice and in HFD-fed mice. Injection of estradiol in Zucker diabetic fatty rats has previously been reported to prevent $\beta$ cell death by suppressing lipid synthesis in insulin-secreting cells (61). However, it is unlikely that the reduction in miR-3383 p expression in obese animals is mediated by GPR30, because GPR30 mRNA levels were unchanged in the islets of HFD-fed mice. Additional experiments will be required to completely rule out a contribution of GPR 30 to $\beta$ cell mass compensation in obesity models. Because GPR30 is expressed in several tissues, and general knockout mice display metabolic perturbations $(42,62)$, the generation of $\beta$ cell-specific GPR30 knockout mice will be required to assess the role of GPR30 in compensatory $\beta$ cell mass expansion in obesity models. Our data suggest that in nonpregnant animals, the level of miR-338-3p may be controlled by incretins. GLP1 was able to downregulate miR-338-3p expression in isolated rat islet cells. Moreover, the level of miR-338-3p was significantly increased in the islets of Glp1 $r^{-/-}$Gip $1 r^{-/-}$mice. A recent study demonstrated IL- 6 -induced production of GLP1 by $\alpha$ cells in pancreatic islets of HFD-fed mice (63). This obesity-induced adaptation process triggered by local production of GLP1 was fully compatible with the miRNA-dependent mechanism of $\beta$ cell mass expansion described herein. The beneficial effects elicited by GLP1 on $\beta$ cells rely on the activation of an autocrine loop that results in a rise in Igf1r and Irs2 (52). These key events in the signaling cascade triggered by GLP1 could be reproduced by miR338-3p downregulation. Moreover, overexpression of this miRNA
A

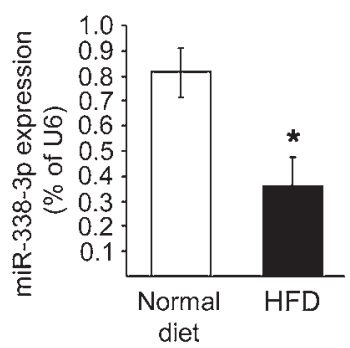

B

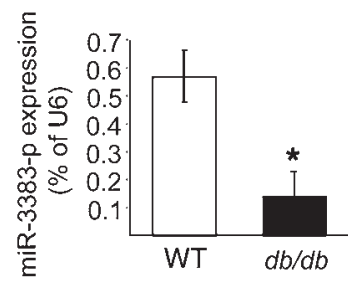

Figure 7

miRNA expression in islets from HFD-fed and $d b / d b$ mice. miR-338$3 p$ levels were measured by qRT-PCR in islets from HFD-fed mice for 8 weeks $(\mathbf{A})$ and in 6-week-old normoglycemic $d b / d b$ mice (B). Data (mean \pm SD of 4 different mice per group) are expressed as percent of U6. ${ }^{*} P<0.05$ vs. control, ANOVA. 

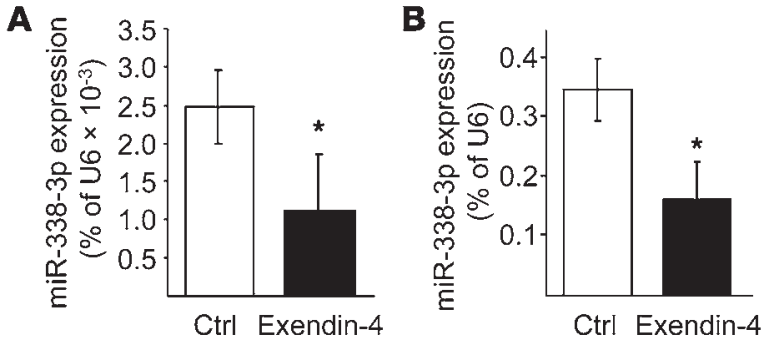

E

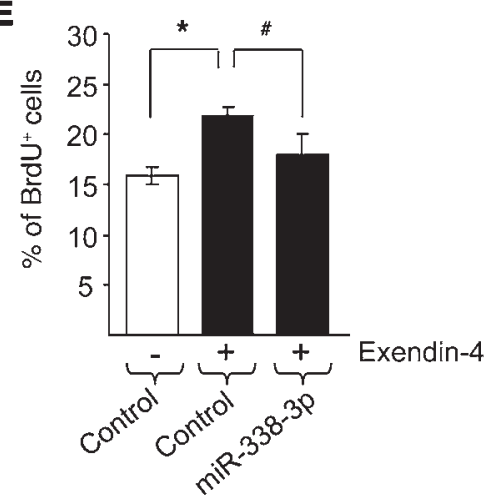

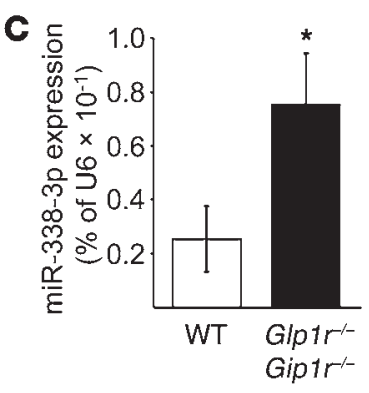

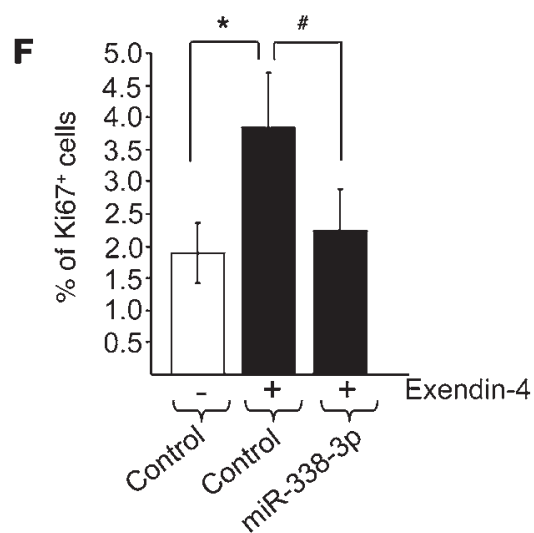

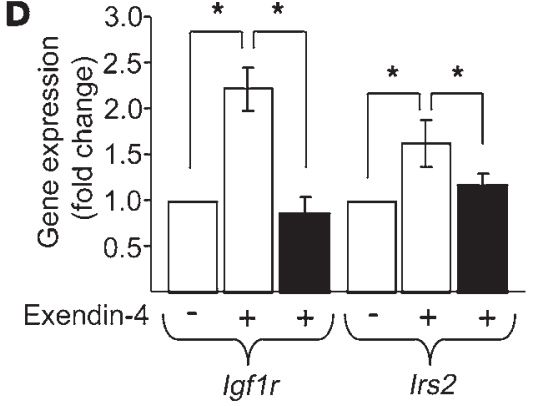

\section{Figure 8}

Incretins signaling and miR-338-3p regulation. Rat $(\mathbf{A})$ or human $(\mathbf{B})$ islets were incubated with or without $100 \mathrm{nM}$ exendin-4 for $48 \mathrm{hours}$. miR338-3p expression was then measured by qRT-PCR. (C) miR-338-3p expression was assessed by qRT-PCR in islets of wild-type and Glp1 $r^{-1-}$ Gip 1 $r^{-1-}$ mice. Results in A-C are expressed as percentage of U6. (D) Rat islet cells were transfected with a control oligonucleotide (white bars) or with an oligonucleotide leading to miR-338-3p overexpression (black bars). Igf1r and Irs2 expression were quantified by qRT-PCR. Results are mean \pm SD of 4 independent experiments. ${ }^{*} P<0.05$ vs. control, ANOVA. INS832/13 cells $(E)$ and dispersed rat islet cells $(F)$ were transfected with a control oligonucleotide or with an oligonucleotide leading to miR-338-3p overexpression. Cells were incubated in the absence or presence of $100 \mathrm{nM}$ exendin-4 for 48 hours. Proliferation was assessed by scoring the fraction of BrdU+ $(\mathbf{E})$ or Ki67 $7^{+}(\mathbf{F})$ cells. Data are mean \pm SD $(n=5$ $[\mathrm{E}] ; 6[\mathrm{~F}]) .{ }^{*} P<0.05$ vs. control, ${ }^{\#} P<0.05$ vs. exendin-4, ANOVA.

prevented the increase in IgfIr and Irs 2 and the enhanced proliferation rate observed in the presence of GLP1, which suggests that a reduction in miR-338-3p level is an important requirement for incretins to achieve full beneficial effects on $\beta$ cells. Our observations indicate that the adaptive changes in $\beta$ cell mass in response to insulin resistance associated with pregnancy and obesity are activated through distinct receptors, but that the downstream signaling pathways they elicit converge and culminate in overlapping modifications in gene expression. Other factors known to induce $\beta$ cell proliferation, such as pituitary adenylate cyclaseactivating polypeptide (PACAP; ref. 64$)$ and glucose $(65,66)$, trigger a rise in cAMP levels. Thus, it is tempting to speculate that at least part of the proliferative effects of these molecules may be achieved by reduction of miR-338-3p expression.

In conclusion, we here unveiled an analogy between the effects of estrogens and incretins on a subset of miRNAs involved in compensatory $\beta$ cell mass expansion occurring during pregnancy and obesity. Our findings have relevant implications for understanding the physiological adaptation of $\beta$ cells to increased insulin demand. Detailed knowledge of the mechanisms controlling the level and activity of the miRNAs differentially expressed during pregnancy may open the way to new therapeutic strategies, with the ultimate goal being to prevent and treat diabetes by promoting $\beta$ cell mass regeneration.

\section{Methods}

Chemicals. Prolactin, 17- $\beta$ estradiol, progesterone, H89, G1, ICI 182-780 (Fulvestrant), dibutyryl cAMP, IL-1 $\beta$, IL-6, palmitate, and exendin-4 were obtained from Sigma-Aldrich. TNF- $\alpha$ was obtained from Enzo Life Sciences, and IFN- $\gamma$ was from R\&D Systems.

Animals. Male, female, and pregnant Wistar rats were obtained from Charles River Laboratories. The sources of $d b / d b$, HFD-fed, and Glp1r-1Gip1r/- mice have been described previously $(48,49,52)$.

Gene expression analysis. Total RNA was isolated with the miRNeasy kit (Qiagen). Measurements of mature miRNA levels were carried out by qRTPCR using the miRCURY LNA Universal RT microRNA PCR kit (Exiqon). Determination of mRNA levels was achieved by conventional qRT-PCR using Bio-Rad Sybr Green reagent (Bio-Rad Laboratories). miRNA expression was normalized to levels of U6 small nuclear ribonucleoprotein or to the level of miR-7. mRNA expression was normalized to the amount of $18 \mathrm{~S}$ present in the same samples.

miRNA profiling was performed at the Genomic Technologies Facility of the University of Lausanne using Agilent Technologies miRNA Gene Microarrays. The dataset is available from the GEO database (accession no. GSE36067). To assess the global effect of miR-338-3p knockdown on mRNA expression, total RNA from INS832/13 cells was analyzed at the Genomic Technologies Facility using the RaGene V1.0 Affymetrix GeneChip. Expression values were normalized using RMA expression summary algorithms (67) implemented in R (version 2.9.2) within the Affyme- 
trix package (68). Statistical analysis was performed with Limma package (69). Probe sets with a $q$ value less than 0.05 were considered differentially expressed with respect to anti-miR-control. The dataset is available from the GEO database (accession no. GSE36067). Biological function and pathway analyses were performed using DAVID (70).

Cell culture. The rat insulin-secreting cell line INS832/13 and the mouse insulin-secreting cell line MIN6B1 were cultured as described previously $(71,72)$. Rat pancreatic islets were isolated by collagenase digestion $(73)$ and then purified on a Histopaque density gradient. They were cultured in RPMI 1640 Glutamax medium (Invitrogen) supplemented with 10\% FCS, $50 \mathrm{U} / \mathrm{ml}$ penicillin, $50 \mu \mathrm{g} / \mathrm{ml}$ streptomycin, and $1 \mathrm{mM}$ sodium pyruvate. Human pancreatic islets were provided by the Cell Isolation and Transplantation Center (University of Geneva, Geneva, Switzerland) thanks to the European Consortium for Islet Transplantation "Islets for Research" distribution program sponsored by the Juvenile Diabetes Research Foundation. Human islets were cultured in CMRL 1066 medium (Invitrogen) supplemented with $10 \% \mathrm{FCS}, 100 \mathrm{U} / \mathrm{ml}$ penicillin, $2 \mathrm{mM}$ L-glutamine, and $25 \mu \mathrm{M}$ HEPES.

Cell transfection. Before transfection, rat and human islets were dissociated by trypsinization and cultured overnight. Dissociated rat and human islet cells, INS832/13 cells, and MIN6 cells were transiently transfected for 48 hours with anti-miR oligonucleotides that specifically block miRNA activity (Qiagen), or with oligonucleotide duplexes mimicking the mature sequence of the miRNAs (Eurogentec) using Lipofectamine 2000 (Invitrogen). A scrambled anti-miR and an siRNA duplex directed against GFP were used as controls. A pool of 4 siRNAs was used to knock down GPR30 expression (ON-TARGET plus SMART pool; Fisher Scientific).

Insulin secretion. Dissociated rat islet cells and MIN6B1 cells were preincubated with KREBS buffer ( $127 \mathrm{mM} \mathrm{NaCl}, 4.7 \mathrm{mM} \mathrm{KCl}, 1 \mathrm{mM} \mathrm{CaCl}_{2}$, $1.2 \mathrm{mM} \mathrm{KH}_{2} \mathrm{PO}_{4}, 1.2 \mathrm{mM} \mathrm{MgSO}_{4}, 25 \mathrm{mM}$ HEPES, $5 \mathrm{mM} \mathrm{NaHCO}_{3}$ ) containing $2 \mathrm{mM}$ glucose (basal condition) for 30 minutes at $37^{\circ} \mathrm{C}$. The medium was then replaced by either the same buffer (basal condition) or a KREBS buffer supplemented with $20 \mathrm{mM}$ glucose (stimulatory condition). After 45 minutes, supernatants were collected, and cellular insulin contents were recovered in $\mathrm{EtOH}$ acid $(75 \% \mathrm{EtOH}, 0.55 \% \mathrm{HCl})$. The amount of insulin in the samples was determined by ELISA (Chemie Brunschwig).

Immunocytochemistry. Dissociated rat islet cells or INS832/13 cells were plated on poly-L-lysine-coated glass coverslips. For BrdU incorporation assays, INS832/13 cells were exposed to BrdU (Roche) for the last 4 hours of culture. The cells were fixed in cold methanol and incubated with PBS supplemented with $0.5 \%$ saponin (Sigma-Aldrich) for 15 minutes. They were then incubated for 30 minutes in blocking buffer (PBS supplemented with $0.5 \%$ saponin and $1 \%$ BSA) and exposed for 1 hour at room temperature to primary antibodies at the following dilutions: 1:1,500 rabbit antiKi67 (Abcam); 1:1,400 mouse anti-BrdU (Cell Signaling); 1:500 guinea pig anti-insulin (Millipore). The coverslips were then incubated for 1 hour at room temperature with goat anti-rabbit Alexa Fluor 488, goat anti-mouse Alexa Fluor 555, and goat anti-guinea pig Alexa Fluor 594 diluted at 1:400 (Invitrogen). Finally, the cells were incubated for 10 minutes with Hoechst 33342 (Invitrogen) and mounted on microscope glass slides with FluorSave mounting medium (VWR International SA). Slides were visualized with a Zeiss Axiovision fluorescence microscope or with a Leica SP5 AOBS confocal microscope.

Islet transplantation. Dissociated rat islet cells were transfected with a scrambled anti-miR or with anti-miR-338-3p and then cultured for 2 days in nonadherent dishes to allow them to aggregate in pseudoislet structures. 500 pseudoislets were transplanted under the left kidney capsule of adult Wistar rats. 2 days after transplantation, the rats were injected with BrdU (100 mg/kg i.p.). The day after, animals were sacrificed, and the kidney bearing the graft was recovered and fixed in $10 \%$ neutral-buffered formalin (Sigma-Aldrich) for 3 days and then embedded in paraffin. The kidneys were sectioned, rehydrated, and incubated with the following primary antibodies: 1:20 mouse anti-BrdU (Roche), 1:200 guinea pig anti-insulin (Dako), 1:200 rabbit anti-glucagon (Dako). Cell nuclei were stained with Hoechst 33342. A minimum of 3,000 insulin ${ }^{+}$cells per kidney was scored with a Zeiss Axiovision fluorescence microscope.

Cell death assessment. Dissociated rat islet cells were plated on poly-L-lysine-coated glass coverslips and stained simultaneously with Annexin V-EGFP, propidium iodide, and Hoechst 33342 (Invitrogen) using the Annexin V-EGFP Apoptosis Detection kit (Biovision). At least 400 cells were analyzed for each condition, by scoring the apoptotic cells (Annexin V-EGFP with or without propidium iodide-positive cells) and necrotic cells (propidium iodide-positive cells). Alternatively, apoptosis was determined by scoring the cells displaying picnotic nuclei upon 10 minutes incubation at room temperature with Hoechst 33342 (Invitrogen). At least 5 fields (about 400 cells) were analyzed for each condition.

Western blot analysis. INS832/13 cells were incubated for 15 minutes on ice in lysis buffer (20 mM Tris, $2 \mathrm{mM}$ EDTA, and protease inhibitors [Roche]). They were then collected, briefly sonicated, and centrifuged to eliminate nuclei and cell debris. The proteins in the supernatants were separated by gel electrophoresis and transferred on PVDF membranes. The membranes were first incubated for 2 hours in blocking buffer $(0.1 \%$ Tween 20 and 5\% BSA [Sigma-Aldrich]), then overnight with the following antibodies: 1:1,000 anti-Birc5 (Cell Signaling); 1:1,000 anti-Bcl2 (Cell Signaling); 1:2,000 rabbit anti-IGF1R (Cell Signaling); 1:20,000 anti-actin (Millipore); 1:14,000 anti-tubulin (Santa Cruz Biotechnology Inc.). Immunoreactive bands were visualized by chemiluminescence (Amersham Biosciences) after 1 hour incubation with horseradish peroxidase-conjugated anti-rabbit and anti-mouse antibodies (Merck). The band intensity was quantified using ImageJ software.

Statistics. Statistical significance was tested by ANOVA followed by post-hoc Bonferroni test (Dunnett's test) when experiments included more than 2 groups. The level of significance was set at $P<0.05$ (SAS statistical package; SAS).

Study approval. All procedures with animals were performed in accordance with NIH guidelines and were approved by the Cantonal Veterinary Office. The use of human islets for research was approved by the Geneva local institutional ethical committee.

\section{Acknowledgments}

We thank Corinne Sinigaglia (Cell Isolation and Transplantation Center, Geneva University, Geneva, Switzerland) for technical assistance. This work was supported by grants of the Swiss National Science Foundation (31003A-127254 to R. Regazzi; 32003B-120376 to D. Bosco), European Foundation for the Study of Diabetes (to R. Regazzi), Société Francophone du Diabète (to C. Jacovetti), National Health and Medical Research Council of Australia (1030715 to R. Laybutt), Fondation pour la Recherche Médicale (to S. Rome), Association Française de recherche sur les Myopathies (to S. Rome), Association Française de Diabétologie (to S. Rome), and Canadian Diabetes Association (to M. Prentki).

Received for publication April 4, 2012, and accepted in revised form July 19, 2012.

Address correspondence to: Romano Regazzi, Department of Cell Biology and Morphology, Rue du Bugnon 9, 1005 Lausanne, Lausanne, Switzerland. Phone: 41.21.692.52.80; Fax: 41.21.692.52.55; E-mail: Romano.Regazzi@unil.ch. 
1. Butler AE, Janson J, Bonner-Weir S, Ritzel R, Rizza RA, Butler PC. Beta-cell deficit and increased betacell apoptosis in humans with type 2 diabetes. Diabetes. 2003;52(1):102-110.

2. Prentki M, Nolan CJ. Islet beta cell failure in type 2 diabetes. J Clin Invest. 2006;116(7):1802-1812.

3. Saisho Y, et al. Ongoing beta-cell turnover in adult nonhuman primates is not adaptively increased in streptozotocin-induced diabetes. Diabetes. 2011;60(3):848-856.

4. Brennand K, Melton D. Slow and steady is the key to beta-cell replication. J Cell Mol Med. 2009;13(3):472-487.

5 . Rhodes CJ. Type 2 diabetes-a matter of beta-cell life and death? Science. 2005;307(5708):380-384.

6. Sachdeva MM, Stoffers DA. Minireview: Meeting the demand for insulin: molecular mechanisms of adaptive postnatal beta-cell mass expansion. $\mathrm{Mol}$ Endocrinol. 2009;23(6):747-758.

7. Hanley SC, et al. \{beta\}-Cell mass dynamics and islet cell plasticity in human type 2 diabetes. Endocrinology. 2010;151(4):1462-1472.

8. Nolan CJ, Damm P, Prentki M. Type 2 diabetes across generations: from pathophysiology to prevention and management. Lancet. 2011; 378(9786):169-181.

9. Parsons JA, Brelje TC, Sorenson RL. Adaptation of islets of Langerhans to pregnancy: increased islet cell proliferation and insulin secretion correlates with the onset of placental lactogen secretion. Endocrinology. 1992;130(3):1459-1466.

10. Van Assche FA, Aerts L, De Prins F. A morphological study of the endocrine pancreas in human pregnancy. BrJ Obstet Gynaecol. 1978;85(11):818-820.

11. Butler AE, et al. Adaptive changes in pancreatic beta cell fractional area and beta cell turnover in human pregnancy. Diabetologia. 2010;53(10):2167-2176.

12. Rieck S, Kaestner KH. Expansion of beta-cell mass in response to pregnancy. Trends Endocrinol Metab. 2010;21(3):151-158.

13. Scaglia L, Smith FE, Bonner-Weir S. Apoptosis contributes to the involution of beta cell mass in the post partum rat pancreas. Endocrinology. 1995;136(12):5461-5468.

14. Huang C, Snider F, Cross JC. Prolactin receptor is required for normal glucose homeostasis and modulation of beta-cell mass during pregnancy. Endocrinology. 2009;150(4):1618-1626.

15. Karnik SK, et al. Menin controls growth of pancreatic beta-cells in pregnant mice and promotes gestational diabetes mellitus. Science. 2007;318(5851):806-809.

16. Zhang $\mathrm{H}$, et al. Gestational diabetes mellitus resulting from impaired beta-cell compensation in the absence of FoxM1, a novel downstream effector of placental lactogen. Diabetes. 2010;59(1):143-152.

17. Kim H, et al. Serotonin regulates pancreatic beta cell mass during pregnancy. Nat Med. 2010; 16(7):804-808.

18. Schraenen A, et al. Placental lactogens induce serotonin biosynthesis in a subset of mouse beta cells during pregnancy. Diabetologia. 2010;53(12):2589-2599.

19. Davis DB, et al. FoxM1 is up-regulated by obesity and stimulates beta-cell proliferation. Mol Endocrinol. 2010;24(9):1822-1834.

20. Sorenson RL, Brelje TC, Roth C. Effects of steroid and lactogenic hormones on islets of Langerhans: a new hypothesis for the role of pregnancy steroids in the adaptation of islets to pregnancy. Endocrinology. 1993;133(5):2227-2234.

21. Brelje TC, Bhagroo NV, Stout LE, Sorenson RL. Beneficial effects of lipids and prolactin on insulin secretion and beta-cell proliferation: a role for lipids in the adaptation of islets to pregnancy. J Endocrinol. 2008;197(2):265-276.

22. Bartel DP. MicroRNAs: target recognition and regulatory functions. Cell. 2009;136(2):215-233.

23. Baek D, Villen J, Shin C, Camargo FD, Gygi SP,
Bartel DP. The impact of microRNAs on protein output. Nature. 2008;455(7209):64-71.

24. Lynn FC, Skewes-Cox P, Kosaka Y, McManus MT, Harfe BD, German MS. MicroRNA expression is required for pancreatic islet cell genesis in the mouse. Diabetes. 2007;56(12):2938-2945.

25. Joglekar MV, Joglekar VM, Hardikar AA. Expression of islet-specific microRNAs during human pancreatic development. Gene Expr Patterns. 2009; 9(2):109-113.

26. Poy MN, et al. A pancreatic islet-specific microRNA regulates insulin secretion. Nature. 2004; 432(7014):226-230

27. Guay C, Roggli E, Nesca V, Jacovetti C, Regazzi R. Diabetes mellitus, a microRNA-related disease? Transl Res. 2011;157(4):253-264.

28. Lovis P, Gattesco S, Regazzi R. Regulation of the expression of components of the exocytotic machinery of insulin-secreting cells by microRNAs. Biol Chem. 2008;389(3):305-312.

29. Baroukh N, et al. MicroRNA-124a regulates Foxa2 expression and intracellular signaling in pancreatic beta-cell lines. J Biol Chem. 2007; 282(27):19575-19588.

30. Lovis $\mathrm{P}$, et al. Alterations in microRNA expression contribute to fatty acid-induced pancreatic betacell dysfunction. Diabetes. 2008;57(10):2728-2736.

31. Roggli E, et al. Involvement of microRNAs in the cytotoxic effects exerted by proinflammatory cytokines on pancreatic beta-cells. Diabetes. 2010;59(4):978-986.

32. Poy MN, et al. miR-375 maintains normal pancreatic alpha- and beta-cell mass. Proc Natl Acad Sci U S A. 2009;106(14):5813-5818

33. Rutti S, Sauter NS, Bouzakri K, Prazak R, Halban PA, Donath MY. In vitro proliferation of adult human beta-cells. PLoS One. 2012;7(4):e35801.

34. Parnaud G, et al. Proliferation of sorted human and rat beta cells. Diabetologia. 2008;51(1):91-100.

35. Donath MY, Boni-Schnetzler M, Ellingsgaard $\mathrm{H}$, Halban PA, Ehses JA. Cytokine production by islets in health and diabetes: cellular origin, regulation and function. Trends Endocrinol Metab. 2010;21(5):261-267.

36. Pirot P, Cardozo AK, Eizirik DL. Mediators and mechanisms of pancreatic beta-cell death in type 1 diabetes. Arq Bras Endocrinol Metabol. 2008;52(2):156-165.

37. Nadal A, Alonso-Magdalena P, Soriano S, Ropero $\mathrm{AB}$, Quesada I. The role of oestrogens in the adaptation of islets to insulin resistance.J Physiol. 2009;587(pt 21):5031-5037.

38. Vasavada RC, et al. Targeted expression of placental lactogen in the beta cells of transgenic mice results in beta cell proliferation, islet mass augmentation, and hypoglycemia. J Biol Chem. 2000;275(20):15399-15406.

39. Le May C, et al. Estrogens protect pancreatic betacells from apoptosis and prevent insulin-deficient diabetes mellitus in mice. Proc Natl Acad Sci U S A. 2006;103(24):9232-9237.

40. Liu S, Mauvais-Jarvis F. Minireview: Estrogenic protection of beta-cell failure in metabolic diseases. Endocrinology. 2010;151(3):859-864.

41. Choi SB, Jang JS, Park S. Estrogen and exercise may enhance beta-cell function and mass via insulin receptor substrate 2 induction in ovariectomized diabetic rats. Endocrinology. 2005;146(11):4786-4794.

42. Martensson UE, et al. Deletion of the G proteincoupled receptor 30 impairs glucose tolerance, reduces bone growth, increases blood pressure, and eliminates estradiol-stimulated insulin release in female mice. Endocrinology. 2009;150(2):687-698.

43. Kumar R, Balhuizen A, Amisten S, Lundquist I, Salehi A. Insulinotropic and antidiabetic effects of 17 beta-estradiol and the GPR30 agonist G-1 on human pancreatic islets. Endocrinology. 2011;152(7):2568-2579.
44. Prossnitz ER, Sklar LA, Oprea TI, Arterburn JB. GPR30: a novel therapeutic target in estrogen-related disease. Trends Pharmacol Sci. 2008;29(3):116-123.

45. Nilsson BO, Olde B, Leeb-Lundberg LM. G proteincoupled oestrogen receptor 1(GPER1)/GPR30: a new player in cardiovascular and metabolic oestrogenic signalling. Br J Pharmacol. 2011;163(6):1131-1139.

46. Filardo EJ, Quinn JA, Frackelton AR, JrBland KI. Estrogen action via the $G$ protein-coupled receptor, GPR30: stimulation of adenylyl cyclase and cAMPmediated attenuation of the epidermal growth factor receptor-to-MAPK signaling axis. Mol Endocrinol. 2002;16(1):70-84

47. Bologa CG, et al. Virtual and biomolecular screening converge on a selective agonist for GPR30. Nat Chem Biol. 2006;2(4):207-212.

48. Peyot ML, et al. Beta-cell failure in diet-induced obese mice stratified according to body weight gain: secretory dysfunction and altered islet lipid metabolism without steatosis or reduced beta-cell mass. Diabetes. 2010;59(9):2178-2187.

49. Kjorholt C, Akerfeldt MC, Biden TJ, Laybutt DR. Chronic hyperglycemia, independent of plasma lipid levels, is sufficient for the loss of beta-cell differentiation and secretory function in the $\mathrm{db} / \mathrm{db}$ mouse model of diabetes. Diabetes. 2005;54(9):2755-2763.

50. Brubaker PL, Drucker DJ. Minireview: Glucagonlike peptides regulate cell proliferation and apoptosis in the pancreas, gut, and central nervous system. Endocrinology. 2004;145(6):2653-2659.

51. Buteau J, Roduit R, Susini S, Prentki M. Glucagonlike peptide- 1 promotes DNA synthesis, activates phosphatidylinositol 3-kinase and increases transcription factor pancreatic and duodenal homeobox gene 1 (PDX-1) DNA binding activity in beta (INS-1)-cells. Diabetologia. 1999;42(7):856-864.

52. Cornu M, Yang JY, Jaccard E, Poussin C, Widmann C, Thorens B. Glucagon-like peptide-1 protects beta-cells against apoptosis by increasing the activity of an IGF-2/IGF-1 receptor autocrine loop. Diabetes. 2009;58(8):1816-1825.

53. Liu $Z$, et al. Insulin and glucagon regulate pancreatic alpha-cell proliferation. PLoS One. 2011;6(1):e16096.

54. Wu X, et al. Perinatal survivin is essential for the establishment of pancreatic beta cell mass in mice. Diabetologia. 2009;52(10):2130-2141.

55 . Rieck $S$, et al. The transcriptional response of the islet to pregnancy in mice. Mol Endocrinol. 2009;23(10):1702-1712.

56. Brelje TC, et al. Effect of homologous placental lactogens, prolactins, and growth hormones on islet B-cell division and insulin secretion in rat, mouse, and human islets: implication for placental lactogen regulation of islet function during pregnancy. Endocrinology. 1993;132(2):879-887.

57. Tiano JP, Mauvais-Jarvis F. Importance of oestrogen receptors to preserve functional betacell mass in diabetes. Nat Rev Endocrinol. 2012; $8(6): 342-351$

58. Prossnitz ER, Arterburn JB, Smith HO, Oprea TI, Sklar LA, Hathaway HJ. Estrogen signaling through the transmembrane $\mathrm{G}$ protein-coupled receptor GPR30. Annu Rev Physiol. 2008;70:165-190.

59. Revankar CM, Cimino DF, Sklar LA, Arterburn JB, Prossnitz ER. A transmembrane intracellular estrogen receptor mediates rapid cell signaling. Science. 2005;307(5715):1625-1630.

60. Liu S, et al. Importance of extranuclear estrogen receptor-alpha and membrane $G$ protein-coupled estrogen receptor in pancreatic islet survival. Diabetes. 2009;58(10):2292-2302.

61 . Tiano JP, et al. Estrogen receptor activation reduces lipid synthesis in pancreatic islets and prevents beta cell failure in rodent models of type 2 diabetes. J Clin Invest. 2011;121(8):3331-3342.

62. Langer $\mathrm{G}$, et al. A critical review of fundamental 
controversies in the field of GPR30 research. Steroids. 2010;75(8-9):603-610.

63. Ellingsgaard $H$, et al. Interleukin- 6 enhances insulin secretion by increasing glucagon-like peptide- 1 secretion from L cells and alpha cells. Nat Med. 2011;17(11):1481-1489.

64. Sakurai Y, Shintani N, Hayata A, Hashimoto H, Baba A. Trophic effects of PACAP on pancreatic islets: a mini-review. J Mol Neurosci. 2011;43(1):3-7.

65 . Porat S, et al. Control of pancreatic beta cell regeneration by glucose metabolism. Cell Metab. 2011;13(4):440-449.

66. Levitt HE, et al. Glucose stimulates human beta cell replication in vivo in islets transplanted into NOD- severe combined immunodeficiency (SCID) mice. Diabetologia. 2011;54(3):572-582.

67. Irizarry RA, et al. Exploration, normalization, and summaries of high density oligonucleotide array probe level data. Biostatistics. 2003;4(2):249-264.

68. Gautier L, Cope L, Bolstad BM, Irizarry RA. affy-analysis of Affymetrix GeneChip data at the probe level. Bioinformatics. 2004;20(3):307-315.

69. Smyth GK. Linear models and empirical bayes methods for assessing differential expression in microarray experiments. Stat Appl Genet Mol Biol. 2004;3:Article3.

70. Huang da W, Sherman BT, Lempicki RA. Bioinformatics enrichment tools: paths toward the com- prehensive functional analysis of large gene lists. Nucleic Acids Res. 2009;37(1):1-13.

71. Hohmeier HE, Mulder H, Chen G, Henkel-Rieger R, Prentki M, Newgard CB. Isolation of INS-1-derived cell lines with robust ATP-sensitive $\mathrm{K}+$ channel-dependent and -independent glucose-stimulated insulin secretion. Diabetes. 2000;49(3):424-430.

72. Lilla V, et al. Differential gene expression in well-regulated and dysregulated pancreatic beta-cell (MIN6) sublines. Endocrinology. 2003;144(4):1368-1379.

73. Gotoh M, et al. Reproducible high yield of rat islets by stationary in vitro digestion following pancreatic ductal or portal venous collagenase injection. Transplantation. 1987;43(5):725-730. 